\title{
243 PHYSICAL ACTIVITY AT THE WORKPLACE IN THE USA
}

Robert Karch Professor, School of Education, Teaching and Health, American University, Washington DC, USA

\subsection{6/bjsm.2010.078725.243}

Most large corporations in the USA realise the benefits of implementing corporate wellness programmes, including a great focus on physical activity. These programmes are often offered by 'forward-thinking' corporations to attract and retain top-level talent, which is key for the success of their corporation. It also makes sense to invest in a healthy workforce, as the benefits are not only an improvement in employee health but also the money savings resulting from a decrease in absenteeism rates and health expenditure - especially in the USA where the cost of health expenditure is at its highest. Corporations are also realising the value of promoting health in the sense of social responsibility, which sets the corporation at a competitive advantage. As a result of these drivers, corporate fitness programmes are becoming more common among large corporations, but also among SMEs due to the increasing evidence of the positive effect of physical activity programmes. The emphasis of physical activity programmes in the workplace has become significant, due to the increasing research showing the importance of incorporating physical activity into daily lives. The workplace setting has demonstrated to be an ideal setting for promoting physical activity due to the following factors:

- the majority of waking time is spent at work

- support from co-workers

- encouragement and motivation team spirit

- easy access

- and the time factor.

A number of leading initiatives that promote physical activity at the workplace have emerged in the USA - for example, the CDC Healthier Worksite Initiative and the National Physical Activity Plan, which encourages various environments, including the workplace setting, to facilitate regular physical activity and reducing sedentary behaviour. Corporations with implemented corporate fitness programmes have seen benefits in various formats; from the increase in morale and productivity to a significant return on investment as a result of a decrease

in health expenditure. Noteworthy is that a successful programme starts with company leaders who engage in corporate fitness programmes and lead by example. 